\title{
Alveolar Stress, How to Measure?
}

Erikson Custódio Alcântara ${ }^{1^{*}}$, Wátila de Moura Sousa ${ }^{1}$, Carlos Oscar Paschetta ${ }^{2}$, Pablo Jorge Galíndez ${ }^{2}$ and Krislainy de Sousa Corrêa ${ }^{1}$

${ }^{1}$ Faculty of Medicine, Federal University of Goias, Professor at the Pontifical Catholic University of Goias/Santa Casa de Misericordia de Goiânia, Brasil ${ }^{2}$ Master in automatic control engineering and electronic engineering from the University of National Technology Cordoba, Argentina

\begin{abstract}
The Alveolar Stress Index is an under explored tool, promising and may help to prevent the deleterious effects of mechanical ventilation. The aim of this study was to describe the importance of Alveolar Stress Index tool, as well as aspects in ventilatory support. This tool evaluates the pressure-volume loop, which, although measures the pulmonary mechanical stress, it does not consider the heterogeneity of the respiratory system. The Alveolar Stress Index, checked in screen monitor of mechanical ventilation equipments, facilitates the detection of alveolar collapse zones (alveolar stress index $<0.9$ ) or overdistension (alveolar stress index $>1.1$ ) of lung areas. If the index value indicates alveolar collapse (atelectrauma=pulmonary lesion caused by the cyclic opening and closing of alveolar units and distal airways), it is recommended to increase the PEEP (Positive end-expiratory pressure). On the other hand, if the value indicates alveolar distension (volutrauma=pulmonary lesion induced by high tidal volume, thus causing the distension of the lung parenchyma), the initial orientation is to decrease the tidal volume. It is worth mentioning that the intention of measuring alveolar stress index is not to replace other parameters, but to add it to patient monitoring, to the median and multicompartmental observation of the ventilated area, considering the heterogeneity of lung ventilation distribution, so that more tools are available to the professional, thus avoiding or hindering lung injuries, when under mechanical ventilation.
\end{abstract}

Keywords: Respiration; Artificial; Alveolar process; Intensive care units

\section{Alveolar Stress Index, how to Measure?}

Mechanical Ventilation (MV) is an indispensable therapy in pathologic cases where adequate oxygenation and respiratory musculature repose are needed [1]. However, while in the MV support, the patient is exposed to several bronchial tree complications with systemic dimensions that can be related to the endotracheal tube, oxygen toxicity, and also with ventilator's direct effects [2].

Once the mechanical ventilator is a potential etiological instrument for likely negative outcomes, an important responsibility is allocated to the Intensive Care Unit (ICU) team. Therefore, the tools and adaptations on this instrument, towards the reduction of the risk which the patient is exposed, are seen as a source of inexhaustible importance, since they are related to the stress put by the MV, referred as Ventilation Induced Lung Injury (VILI) [1].

The harmful ventilatory patterns detection and identification on patients under MV support is almost impossible when using conventional means, or at least very dependant of accompaniment and a narrow evaluation, due to the lungs heterogeneous nature. Therefore, enhanced functions and tools on these equipments are ideal to the objective and therapeutic control. The Alveolar Stress Index is a promising and under explored tool, that can contribute to avoid such potential risk events. In this context, the purpose of this study was to describe the importance of the Alveolar Stress measurement, as well as its aspects on the ventilatory support.

\section{Alveolar Stress Tool}

Pathological findings involved in the lung lesion are associated to biotrauma, lesion process where biophysical forces modify the lung cells regular physiological state, culminating on the increase of inflammatory mediators level and promoting the repair and/or remodeling of the tissue, with the hyaline membrane increase. With the result, there is the diffuse alveolar damage, marked by the presence of monocytes, macrophages and neutrophils in acute and exudative phase of acute lung injury $[1,3]$.

Figure 1 demonstrates the deformation of the alveolar wall in a patient exposed to inappropriate ventilation parameters. It should be noted an alveolar wall with irregular borders, combining zone of alveolar collapse and zone of overdistension. This phenomenon will be later called by professional intensivists as biotrauma.

During the artificial ventilation, the lungs are exposed to three mechanical forces which increase the chances of lung injuries and are directly associated to the mechanisms that generate or potentialize the alveolar stress, such as: respiratory system stress, strain and shear stress $[4,5]$.

The respiratory system stress is defined as the distribution of forces applied per unit of lung area, represented on the respiratory system by the transpulmonary pressure [5]. The stress generated by the biotrauma can initiate or aggravate a local and systemic inflammatory response [1]. The strain is a stretch or deformation of a pulmonary structure or region in function of a force application, caused for example, by an excessive alveolar distension in consequence of elevated tidal volumes [5], it offers changes in the relative length compared to the alveolus's original length. The shear stress is defined as a frictional force that acts in parallel to the cell surface in the fluid-solid interface, is generated when fluids like air or blood move through the cell surface [6].

Professionals in the field and researchers discuss about alveolar stress and both parties agree with the need to provoke the minimum of stress in an already damaged lung [7], once the regular alveolus overdistension and collapsed alveolus open-close movements contribute to the lung lesion progression, in consequence of both

*Corresponding author: Erikson Custódio Alcântara, Faculty of Medicine, Federal University of Goias, Professor at the Pontifical Catholic University of Goias/Santa Casa de Misericordia de Goiânia, Brazil, Tel: 55-62-91663824; E-mail: krislainycorrea@hotmail.com

Received January 20, 2015; Accepted July 15, 2015; Published July 20, 2015

Citation: Alcântara EC, Sousa WdM, Paschetta CO, Galíndez PJ, Corrêa KdS (2015) Alveolar Stress, How to Measure?. J Pulm Respir Med 5: 273. doi:10.4172/2161-105X.1000273

Copyright: (c) 2015 Alcântara EC, et al. This is an open-access article distributed under the terms of the Creative Commons Attribution License, which permits unrestricted use, distribution, and reproduction in any medium, provided the original author and source are credited. 


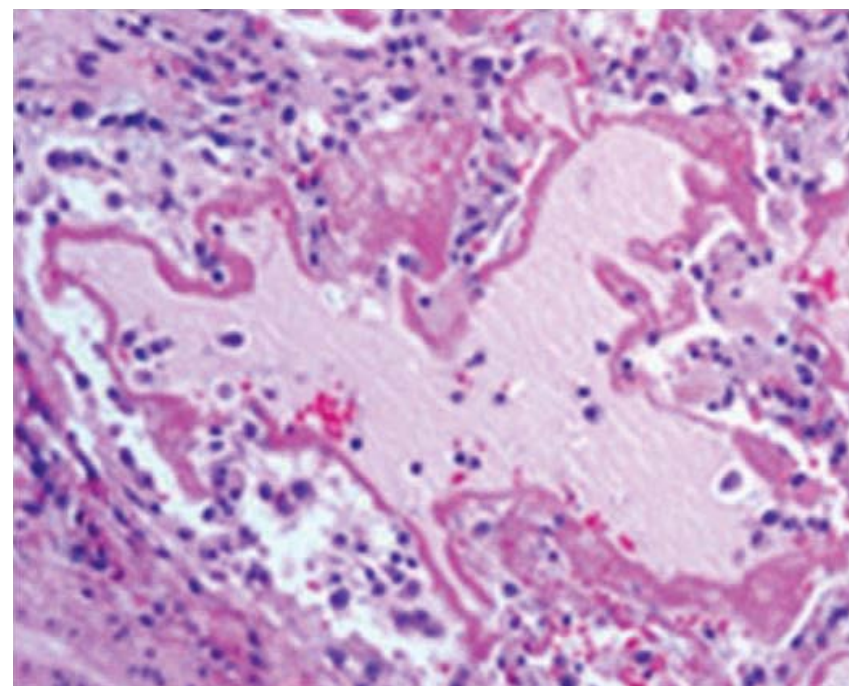

Figure 1: Representative image of alveolar stress [3].

installed pathologic process, as the impact of the offered mechanical ventilation [8]. Thereby, a special attention to the alveolar ventilation monitoring which is offered to the patient must be provided.

The Computed Tomography (CT) is an option to follow this kind of support, because it demonstrates in a dynamic way the moment when the alveolus opens and closes according to the offered volume, avoiding the exposure to alveolar stress, however the use and availability of a $\mathrm{CT}$ is not a reality in every bed on several healthcare centers [7]. Yet there is the pressure-volume loop (PV), a graphic representation which provides data regarding the ventilation, good tool intended to minimize the mechanical tension applied to the pulmonary parenchyma. However the PV loop has an unicompartmental focus, in other words, it is able to demonstrate the whole lung and does not consider its heterogeneity. It can influence the lung areas that were not recruited or already distended - confusion factor in the alveolar recruiting maneuver, since both the recruitment as the alveolar distention can occur at the same time on different areas in the respiratory system [9]. The loop can demonstrate a good progressive linearity for the alveolar recruitment and underestimate areas where the alveolus are in recruitment process [7].

In this context, the alveolar stress measurement is a parameter present in the mechanical ventilation monitor, which contributes to detect and prevent potentially harmful situations [10].

Alveolar stress measure is not intended to replace the PV loop, but to add it to patient monitoring, to the median and multicompartmental observation of the ventilated area, considering the heterogeneity of lung ventilation distribution $[10,11]$.

This mechanical ventilation tool is useful to patients in the aid of an MV, because it allows the identification of the PEEP (Positive endexpiratory pressure) level and the tidal volume, causing the respiratory system minimum stress. It is applied mainly in patients with Acute Respiratory Distress Syndrome (ARDS), because during the first days, this condition contributes to lower alveolar lesion with possible mortality reduction [12].

The alveolar stress measurement also allows to quantify in a subjective way if the ventilation applied to the patient is occurring within a safe zone, avoiding alveolar collapse and overdistension [10].

\section{Interpretation of the Curve and Measure Values of the Alveolar Stress}

Alveolar stress measure can be interpreted by an absolute and dimensionless numerical value as well as by pressure $\mathrm{x}$ time curve behavior in presence of constant flow. The straight curve represents stress value between 0,9 and 1,1 considered as normal, also said as the minimum stress value inflicted in the alveoli (safety zone). The convex curve represents values lower than 0,9 and for the concave curve, values superior than $1,1[10,11]$.

If the index value is lower than 0,9 and with convex form, it is estimated that there is alveolar collapse (atelectrauma=pulmonary lesion caused by the cyclic opening and closing of alveolar units and distal airways), this is why it is recommended to increase the PEEP. On the other hand, if the value is superior than 1,1 followed by concave curve, there is probably alveolar distension (volutrauma=pulmonary lesion induced by high tidal volume, thus causing the distension of the lung parenchyma), the initial orientation is to decrease the tidal volume. Thus, the possible parameters to be adjusted on the ventilator to minimize stress are alveolar PEEP and tidal volume [10,11].

Therefore, alveolar stress measure suggests that even though the PV curve graphically demonstrates the rise and/or reduction of lung compliance, when pointing to a value equal to 1.0, we may consider that the mechanical ventilation support causes the minimum stress generated in the alveolus $[10,11,13]$. The Figure 2 demonstrates the association between the PV curve, dimensionless values and the alveolar stress curve (Figure 2).

The alveolar stress measure quantifies the alveolar collapse or overdistension, it does not offer information about the lung compliance, as this is the pressure $\mathrm{x}$ volume curve's role.

Despite the knowledge of the advantages in obtaining the analysis of the ventilation by considering the lung heterogeneity through alveolar

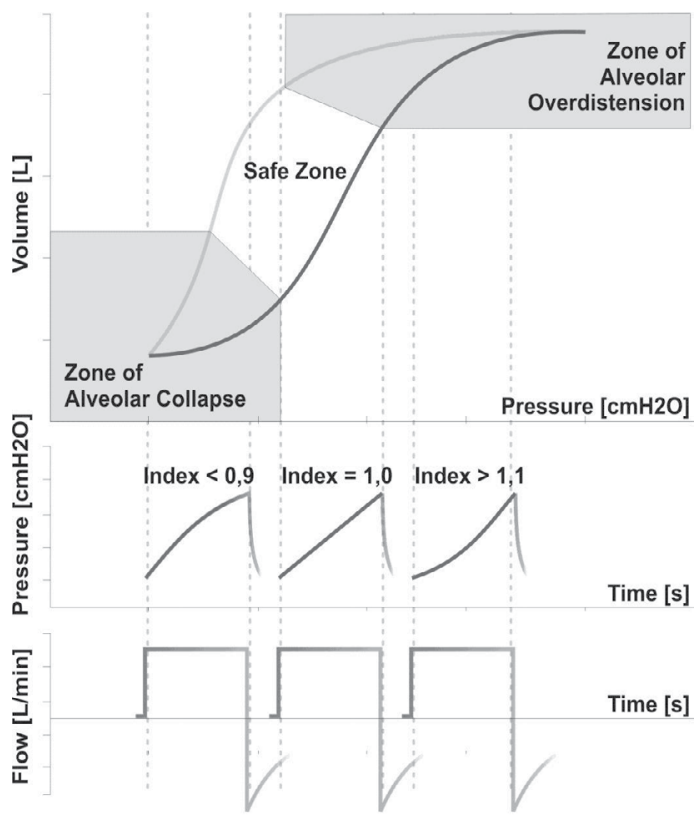

Figure 2: Representative figure of the pressure-volume loop, highlighting the zones of alveolar collapse and overdistension. Below that, the volume-pressure curve shows the behavior of the pressure-time curve with constant flow. 
stress, other elements must be studied, such as possible influences due to tidal volume variation, influences of decubitus variation in stress measure and to find out and to detail if flow variation influence the calculation of alveolar stress. Such enquiries may be crucial for a question that yet old, it is still pertinent nowadays: "Will the alveolar stress measure as mechanical ventilation tool be able to guide the mechanical ventilation professional to provoke the minimum LPIV as well as mortality in our ICU?".

Henceforth it is understood this is just a timid step to initiate new discussions about the topic, alveolar stress.

\section{References}

1. Nardelli LM, Garcia CS, Pássaro CP, Rocco PR (2007) [Understanding the mechanisms of ventilator-induced lung injury]. Rev Bras Ter Intensiva 19: 469474

2. Tallo FS, Vendrame LS, Lopes RD, Lopes AC (2013) Ventilação mecânica invasiva na sala de emergência: uma revisão para o clínico. Rev Bras Clin Med. São Paulo 11: 48-54.

3. Matthay MA, Song Y, Bai C, Jones KD (2013) The acute respiratory distress syndrome in 2013. Translational Respiratory Medicine 10: 1-6.

4. Fanelli V, Vlachou A, Ghannadian S, Simonetti U, Slutsky AS, et al. (2013) Acute respiratory distress syndrome: new definition, current and future therapeutic options. J Thorac Dis 5: 326-334.

5. Rocco PRM, Zin WA (2009) Fisioterapia: teoria e prática clínica - fisiologia respiratória aplicada. RJ, Guanabara Koogan.

6. Oeckler RA, Hubmayr RD (2008) Cell wounding and repair in ventilator injured lungs. Respir Physiol Neurobiol 163: 44-53.

7. Marini J (2008) The stress index. Focus Journal.

8. Terragni PP, Rosboch GL, Lisi A, Viale AG, Ranieri VM (2003) How respiratory system mechanics may help in minimising ventilator-induced lung injury in ARDS patients. Eur Respir J Suppl 42: 15s-21s.

9. Muñiz-Albaiceta G (2009) [Pressure-volume curves in acute pulmonary injury] Med Intensiva 33: 243-250.

10. Pascheta C, Alcântara EC (2014) Índice de Estrés en el ventilador Leistung modelo LUFT3.

11. Ranieri M, Zhang H, Mascia L, Aubin M, Lin C, et al. (2000) Pressure time curve predicts, minimally injurious ventilatory strategy in an isolated rat lung model. Anesthesiology 93: 1320-1328.

12. Papazian L, Forel JM, Gacouin A, Penot-Ragon C, Perrin G, et al. (2010) Neuromuscular blockers in early acute respiratory distress syndrome. N Engl J Med 363: 1107-1116.

13. Grasso S, Stripoli T, De Michele M, Bruno F, Moschetta M, et al (2007) ARDSnet ventilatory protocol and alveolar hyperinflation: role of positive endexpiratory pressure. Am J Respir Crit Care Med 176: 761-767. 